\title{
Antimicrobial Resistance in Agriculture
}

\author{
Sophie Thanner, a David Drissner, ${ }^{\text {b }}$ Fiona Walsh ${ }^{c}$ \\ Agroscope, Institute for Livestock Sciences, Posieux, Switzerlanda; Agroscope, Institute for Food Sciences, Waedenswil, Switzerlandb; Department of Biology, Maynooth \\ University, Maynooth, County Kildare, Irelandc
}

\begin{abstract}
In this article, the current knowledge and knowledge gaps in the emergence and spread of antimicrobial resistance $(A M R)$ in livestock and plants and importance in terms of animal and human health are discussed. Some recommendations are provided for generation of the data required in order to develop risk assessments for AMR within agriculture and for risks through the food chain to animals and humans.
\end{abstract}

\begin{abstract}
ntimicrobial agents have revolutionized medicine in many
respects, but their use has been accompanied by a rapid appearance of resistant strains for many decades, resulting in a global health problem. The latest global report on surveillance of antimicrobial resistance (AMR) (1) highlighted the major gaps in data on AMR in foodborne bacteria and their potential impacts on both animal and human health. The bacteria involved in the transfer of AMR are not limited to foodborne pathogens but include commensals and environmental microbes. There is limited knowledge concerning the transmission of AMR within agricultural sites and to humans via foods of animal and plant origins, as well as human health risks posed by the agricultural release of antimicrobial agents (AMA), antimicrobial resistance genes (ARG), and antimicrobial-resistant bacteria (ARB) into the environment. However, food animals are not only vehicles of AMR transmission but also are endpoints in the dissemination, selection, and spread of ARB and ARG.

Switzerland has a history of excellent research in the relevant fields of science and has long-established surveillance laboratories. We have utilized the data generated in Switzerland as a data set to model the global situation and to demonstrate the available knowledge in relation to AMR in plant and animal agriculture and their roles as sources and sinks of AMR (Fig. 1). Through these data, we have identified common gaps in our knowledge (Table 1) and have made some recommendations to generate the data required in order to develop risk assessments of AMR within agriculture and through the food chain to animals and humans.
\end{abstract}

\section{STEP 1. IDENTIFYING THE AVAILABLE KNOWLEDGE}

The latest Swiss surveillance report showed that 49,250 kg of AMA for veterinary use was sold in Switzerland in 2014 (2). Currently, only the total quantity of the various AMA classes sold is monitored, as there is, in contrast to the defined daily dose (DDD) for humans (3), no established system of measurement for veterinary drug utilization. In an effort to link the amount of sold AMA to the population size, the population correction unit (PCU) (4) was used.

After the ban of antimicrobial growth promoters (AGP) in Switzerland in 1999, the use of orally administered AMA via feed or drinking water for prophylactic and metaphylactic uses is still allowed with veterinary prescription, resulting in frequent exposure of entire groups of animals, healthy and diseased, to AMA. This is reflected by the fact that $59 \%$ of all AMA sold for veterinary use were medicated premixes for oral administration to farm animals (2). AMA sold in the greatest amounts in Switzerland were sulfonamides, penicillins, and tetracyclines, which comprise about $82 \%$ of all AMA sold (2). The use of highest-priority, critically important antimicrobials, such as third- and fourthgeneration cephalosporins, fluoroquinolones, and macrolides for animal use, is of the greatest concern (5). While not all AMA used in animal health are used in human medicine, most of the AMA used in livestock have identical or very similar structures to those used in human medicine.

Complex transmission routes within farm animals and between farm animals and humans, as well as the frequent transfer of ARG among host bacteria, make it difficult to demonstrate whether a reservoir of AMR in farm animals poses a risk for animal or human health (6). The current approach to assess the reservoir of ARG in livestock is to analyze the level of AMR of zoonotic agents and commensal bacteria in healthy farm animals at slaughter. These results are also included in the annually published EU summary reports of the European Food Safety Authority (EFSA) and European Centre for Disease Prevention and Control (ECDC) (7). Since 2006, the Swiss State laboratories have performed standardized testing of indicator bacteria in broilers, pigs, and cattle for antibiotic resistance. In 2014, meat samples within Switzerland were investigated for the presence of ARB. The results indicated that $6.9 \%$ of broiler meat samples carried methicillin-resistant Staphylococcus aureus (MRSA) and 73.3\% contained extended-spectrum beta-lactamase (ESBL)-producing or AmpC beta-lactamase-producing Escherichia coli (2). In addition, research studies have shown the presence of ARB in foods of animal origin from Switzerland (8-10).

While there is certain knowledge of AMR in Swiss livestock and their products, the quantities of AMA, ARB, and their ARG in manure are not monitored. This brings cause for concern, as animals do not transform all administered AMA into inactive compounds before excretion and, therefore, a large proportion of AMA retain their antimicrobial activities after renal or biliary excretion (11). In addition, during manure storage, inactivated conjugates may revert back to their parent compounds (11). International studies have examined the fate of AMA during different treatments of manure (12-14), but no conclusive recommenda-

\section{Published 19 April 2016}

Citation Thanner S, Drissner D, Walsh F. 2016. Antimicrobial resistance in agriculture. mBio 7(2):e02227-15. doi:10.1128/mBio.02227-15

Editor Fernando Baquero, Ramón y Cajal University Hospital

Copyright $\odot 2016$ Thanner et al. This is an open-access article distributed under the terms of the Creative Commons Attribution-Noncommercial-ShareAlike 3.0 Unported license, which permits unrestricted noncommercial use, distribution, and reproduction in any medium, provided the original author and source are credited.

Address correspondence to Fiona Walsh, Fiona.Walsh@nuim.ie. 


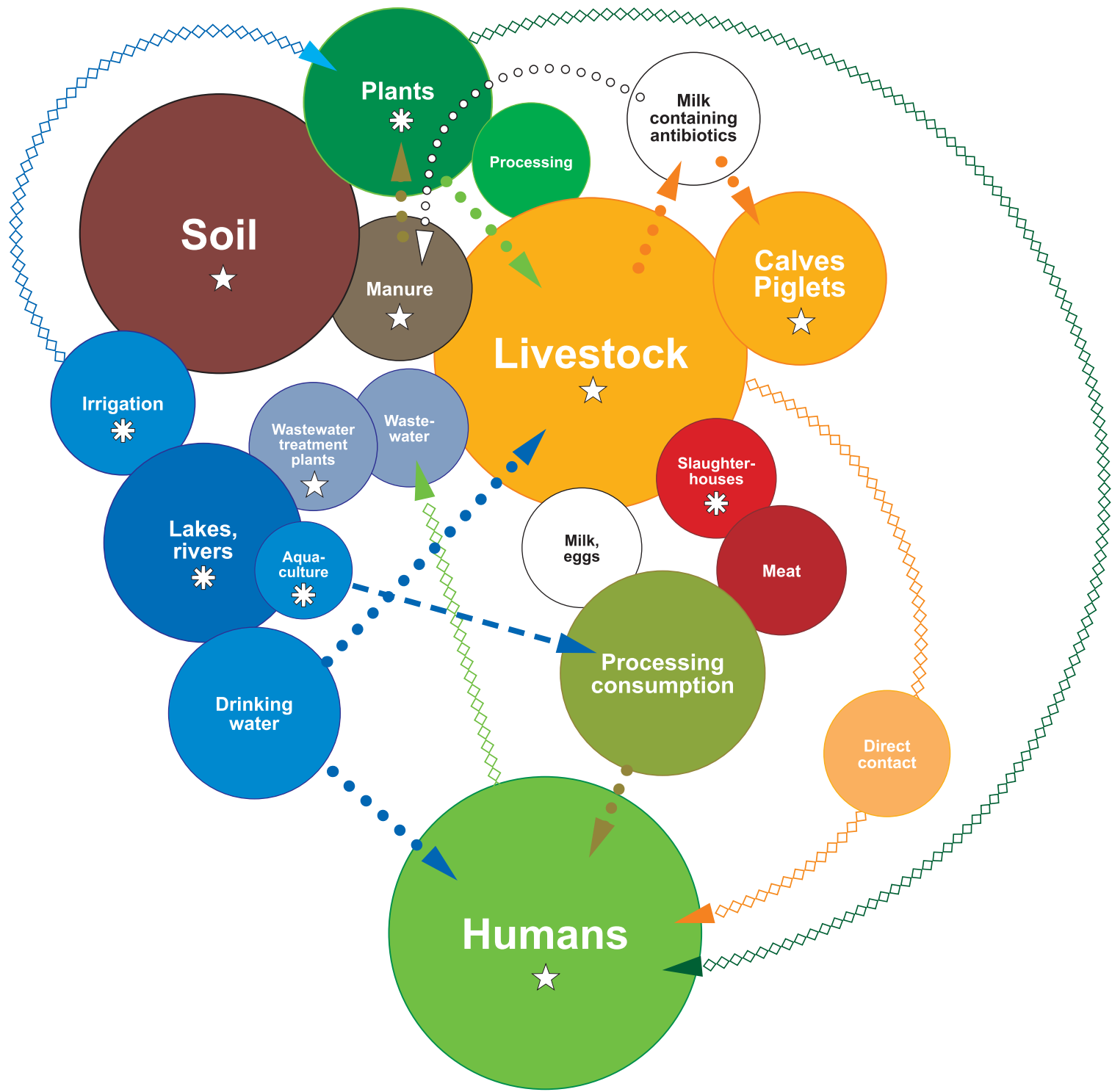

FIG 1 Pathway map of AMA and AMR dissemination within agriculture, the environment, and the food processing industry. Movement of AMA or AMR is indicated by overlapping circles and arrows, respectively; different colors define different groups of reservoirs. Stars indicate the hot spots of ARG and ARB with high bacterial densities, nutrient availability, and selective pressure in the digestive tract of livestock and humans, in manure storage facilities, wastewater treatment plants, and in the rhizosphere. Asterisks indicate possible hot spots of ARG and ARB in water, sediments, and biofilms in aquaculture, rivers, lakes, and irrigation systems, as well as in slaughterhouse facilities and on plant surfaces.

tions to eliminate AMA, as well as ARB and ARG, are available. This is partly due to the variety of chemical properties of AMA, manure-related matrix characteristics modifying their biodegradability (15), and the differences in the resilience of host bacteria or ARG to manure treatment, where a complex microbial ecology is involved.

It has been shown that manure is a "hot spot" of bacteria carrying ARG residing on mobile genetic elements (MGE) (Fig. 1) $(16,17)$. When soils are treated with manure, AMA and their metabolites as well as bacteria carrying ARG are introduced into the soil. In soil, ARG are likely to be horizontally transferred to soil bacteria, a process that is enhanced by manure (18). Factors influencing ARG dissipation rates from introduced bacterial hosts include the transport of bacteria hosting ARG, vertical and horizon- tal transfer of ARG, the transport of extracellular DNA containing ARG, the binding of ARG to soil or organic matter, the decay of extracellular ARG, and the decline of bacterial hosts (19). Repeated application of manure containing AMA may result in an enrichment of taxa that also include human pathogens and a reduction of bacteria that contribute to soil quality (20). Additionally, soil itself represents a natural reservoir for ARB carrying a diverse set of known and unknown $\operatorname{AMR}$ determinants $(21,22)$, and these might be influenced by selective pressure due to application of AMA, as the resilience of a soil bacterial community against disturbance from manure application decreases in the presence of certain AMA (Fig. 1) (20). The pollution of the environment by AMA and ARG probably increases the chance of commensal bacteria and human pathogens to acquire AMR by MGE, 
such as broad-host-range plasmids facilitating horizontal gene transfer (HGT) between distantly related species (23).

In addition to the influence of bacterial soil community and selection for AMR, the introduction of AMA to soils also results in uptake of AMA into plants, mainly through water transport and passive absorption (24). There is limited understanding of the interactions of AMA concentrations in manure and soil, AMA chemical characteristics, characteristics of specific crops, the plant growth stage, and plant physiology on plant uptake of AMA. Since treated wastewater and lake water have been shown to contain ARG (25), water obtained close to such sources for irrigation purposes in plant production may pose a risk for transmission of ARB and ARG onto fresh produce (Fig. 1). Irrigation water is generally regarded as one of the important bacterial contamination sources in vegetable growth during the preharvest phase (26). Much research has been performed on pathogens and foodborne diseases, and several studies detected resistant bacteria on vegetables and fruits (27-29), including in Switzerland (30), but data for use toward establishing a direct relationship between irrigation water or manure containing $\mathrm{ARB}$ and $\mathrm{ARG}$ and the abundance and spread of corresponding bacteria or ARG on produce are scarce.

The use of AMA in plant production, both from a qualitative and quantitative point of view, is minimal compared to their use in animal health protection or human medicine. Since these AMA are usually sprayed over the plant and therefore are distributed also to soil and possibly to neighboring water systems, their potential influence on environmental, animal, and human resistomes are worth noting. The use of AMA in plant agriculture in Switzerland and EU countries is restricted to streptomycin in the prevention of fire blight disease in apple and pear trees, which is caused by the phytopathogenic enterobacterium Erwinia amylovora. Controlled streptomycin treatment had no stable long-term effect on the prevalence of streptomycin and tetracycline ARG in flowers, leaves, and soil samples of orchards, nor did it significantly alter the bacterial populations of the soil in apple orchards (31-33). This lack of selection may be due in part to the strong sequestration of streptomycin in soil. However, studies must be performed on the use of each antibiotic in its context due to the complex properties of agricultural environments, where stability and activity of AMA may be strongly affected by adsorption to soil particles, dilution by rainfall, or degradation by radiation or microorganisms. The environment and soil are important past, current, and potentially future reservoirs of clinically relevant ARB (34) and thus must be considered in the evaluation of risk factors contributing to the global spread of AMR.

\section{STEP 2. IDENTIFYING THE LIMITATIONS OF OUR CURRENT DATA}

Monitoring and testing AMA use and AMR within agricultural systems. Although the annual Swiss surveillance report (2) is an important step to monitor the use of AMA for animal health, these data do not provide information on indication, the frequency of administration per animal, trade names of the AMA, or species treated. Therefore, a new, centralized database for monitoring the use of AMA is being established (35). Further harmonization with the European Antimicrobial Resistance Surveillance Network (EARS-Net) and the Pan American Health Organization (PAHO), as well as profound specifications for the standardization of monitoring AMR in animals, is needed. In addition, the cumulative effects of AMA use on the absolute amount of bacteria carrying
ARG that are able to colonize humans in manure, soil, water bodies, and livestock need to be addressed. There is no monitoring system for the complex transmission routes of AMA, ARG, and ARB from manure to soil, aqueous environments, plant products, and back to livestock and humans. This is of particular concern, as manure and wastewater treatment plants (WWTP) are reservoirs of AMR (36) and could be utilized as critical control points, where the release of complex mixtures of AMA, ARG, and ARB from farm and urban surroundings to the environment could be controlled. It has to be noted that, due to the key processes of sorption and sequestration that govern the chemical and biological availability of AMA, different extraction methods will result in different quantitative interpretations of their concentrations in manure and soil. Moreover, when analyzing trace levels of AMA in the presence of a complex matrix, information on the nature, effect, and behavior of biodegradation products of AMA is required (37). In order to compare results nationally and internationally, a monitoring system needs to be established that provides precise specifications for the standardization of methods for monitoring AMR and AMA concentrations in manure and soil.

The limitations of current methods and breakpoint criteria to define the levels of ARB of clinical relevance in environmental samples in comparison to clinical samples have been documented (38). To overcome the limited information of nonpathogenic environmental species, which can be important carriers of ARG, in databases used for the estimation of epidemiological cutoffs (ECOFFs), it is essential to add additional data from environmental species, isolates, and ARG described in environmental bacteria. Alternatively, an "ecological breakpoint" can be envisaged that uses the AMA concentrations able to select a particular population of ARB in environmental or animal or manure samples as the breakpoint. The "ecological breakpoint" should take the natural AMR in the natural bacterial community into consideration, where potentially pathogenic ARB are not expected to be selected due to competition with intrinsic resistant environmental bacteria. Similar difficulties and limitations are present in measuring AMR in the phyllosphere and to a lesser extent in commensal bacteria in livestock.

Identifying the factors that cause the selection, spread, and persistence of ARG and ARB. The increased presence of AMR is usually caused by the selective pressure of AMA or coselecting agents, such as metals, disinfectants, or biocides (39). Not only therapeutic doses of AMA but also subinhibitory concentrations can cause selection and enrichment of ARB (40). The causal relationship is not always obvious, as the diversity and interrelation of potential causes for an observed AMR and its persistence are set in a multiparameter space (41). The situation is made more complex when AMR is mediated by ARG associated with MGE, such as integrons and plasmids (42), and not by mutation. In these cases, the development of a resistance mechanism, the emergence of the pathogen, and the enrichment and transmission of the pathogenic ARB often occur in different environments and are therefore difficult to retrace. Furthermore, biofilms are hypothesized to be crucial for bacterial survival in food processing plants (43), water systems (44), and the phyllosphere (45). Novel metagenomics technologies offer the possibility to elucidate ARG in environmental, human, and animal microbiomes and to add to the identification of factors causing their selection, spread, and persistence. Antibiotic resistance genes detected in this way have been ranked recently into seven categories of the resistance readiness 
condition (Rescon), which is defined by the risk of acquiring and conferring ABR to human pathogens (46). Antibiotic resistance genes, which are known to compromise antibiotic therapy and are present on MGE in pathogens, are categorized in the highest Rescon (Rescon 1). Such risk systems classifying AR genes are promising tools to clearly assess public health risks.

Understanding the transfer pathways of ARG and ARB. Animal populations are exposed to ARG and ARB via the food chain or due to environmental pollution. How this occurs and the role of manure or feed treatment, such as drying or ensiling, are not known. Human populations are exposed to ARB of animal origin through direct contact with animals or via consumption of animal products, as well as through widespread release of ARG into the environment. The multiple pathways (Fig. 1) of gene exchange have so far defeated attempts to qualitatively or quantitatively track the movement of these genes in vivo. With the exception of zoonotic bacteria, extensive gene movement between several hosts makes it less likely that the same bacterial hosts will be found in animals and humans and more probable that only the ARG themselves will be identifiable in the final pathogens that infect humans (Fig. 1) (6). Even the ARG themselves may be altered during their passage through multiple intermediate hosts (47) or may be unexpressed and therefore not detected by phenotypic susceptibility tests. Thus, it is important that surveillance programs not only focus on pathogenic ARB but also determine the ARB together with the ARG they are carrying.

As there is still a lack of knowledge concerning factors that influence the spread of AMR, most mathematical models that try to predict the impacts of the use of AMA in farm animals on diseases in humans caused by ARB are deliberately simplified, and many aspects of transmission and persistence, like the contribution made by commensals, are ignored. They are mostly based on multiple assumptions, often concentrate on just a single pathogenic ARB rather than on the resistome in total, and limit the outcome on determination of lethality while ignoring the incidence of diseases and prevalence of ARG. As there is some evidence that the environmental resistome has the potential to be at least partly transferred to pathogens, the strategies to reduce AMR in animals and humans should include the prevention of gene flow to and from environmental AMR reservoirs (48). This can be achieved by limiting agricultural sources (optimizing AMA use, maintaining good animal health, use alternatives to antibiotics) and finding efficient methods to manage manure and domestic, hospital, and industrial wastewater containing AMA and ARG. In general, while there are data from competition experiments (49), recent mathematical models lack knowledge of microbial loads, ignore biological mechanisms of within-host competition, and cross-species spread of AMR by plasmid transfer at each stage of the "farm-to-fork" transmission chain $(6,50,51)$.

State-of-the-art methods used to study abundance and transferability of ARG. Surveillance laboratories currently use culture and PCR-based methods to determine the ARB and ARG profiles of pathogenic bacteria. However, the major limitations of these approaches are that only bacteria capable of growing under laboratory conditions are identified, and the requirement for prior knowledge of the resistance genes being investigated to enable primer design. As there are potentially hundreds of resistance genes present in, for example, a manure sample, the number of PCRs required to test the sample using PCR alone for all genes is neither realistic nor cost-effective. However, advances in the past decade in molecular biology now enable us to use other techniques to screen the total DNA of a sample for ARG, antibiotic resistance proteins, and AR-carrying plasmids. The development of AR gene detection chips or chips to detect the relative abundances of ARG in extracted DNA have considerably reduced the costs of screening total DNA samples for hundreds of resistance genes and removed the requirement for bacterial isolation (52).

Metagenomics and next-generation sequencing (NGS) enable the detection of millions of genes within a sample of DNA. While there are still limitations in terms of the minimum copy number of a gene in order for it to be detected, metagenomics has enabled the exploration of complex microbiomes for the presence of all known ARG. Although the reconstruction of plasmids within metagenomic data is difficult due to the mosaic nature of plasmids, with similar or identical sequences of considerable length, obtaining correctly closed genomes of large plasmids remains a challenge for metagenomic analysis of complex microbiomes. Methods such as single-molecule real-time sequencing (SMRT) applied by Pacific Biosciences are very promising for plasmid genome sequencing, as fragments as long as $40 \mathrm{~kb}$ can be sequenced in one read. Through use of whole-genome analysis, novel resistance single nucleotide polymorphisms (SNPs) may now be identified by comparison of many resistant bacterial isolates, which show a resistance phenotype but do not contain any of the known resistance mechanisms. Plasmid sequence analysis may also be performed using NGS. While the problem of plasmid construction is difficult, it recently became feasible, thanks to tools such as PLACNET (plasmid constellation networks).

Other tools include functional metagenomics to identify novel resistance genes. This requires a longer time frame than metagenomics but has the advantage of starting with the identification of a resistance phenotype. Microarray expression analysis has provided great insights into the expression profiles of specific bacteria under antibiotic stress. The more recent versions of transcriptomics and metatranscriptomics tools identify the expression or transcripts of genes present in a sample. While these tools are not yet as popular as metagenomics and whole-genome sequencing, they too can identify the functional genes present in samples. This may be particularly useful in terms of understanding the dynamics of resistance gene expression through, for example, the food chain or from animal feces to manure to soil.

Analytical methods used to determine the fate of AMA in organic wastes or in soils. There are very few data on the concentrations of antibiotics in environmental samples. This may be due, at least in part, to the lack of analytical methods for monitoring contaminants in waste, surface and drinking water quality, and soil. For many years, the analysis of organic microcontaminants has been performed via high-performance liquid chromatography coupled to UV detection (HPLC-UV) and gas chromatography (GC) coupled to flame ionization detection (GC-FID), electron capture detection (GC-ECD), and mass spectrometry (GC-MS) (53). However, liquid chromatography coupled to mass spectrometry (LC-MS) has largely replaced GC methods. LC-MS presents various advantages, such as reduced sample pretreatment and the capability to determine very polar compounds and transformation products without modifying the chemical $(54,55)$. Although the use of MS, and especially tandem MS (MS-MS), allows increased sensitivity, an analyte preconcentration procedure is almost always necessary to reach limits of detection low enough to determine the ultratrace levels at which emerging contaminants, 
TABLE 1 Knowledge gaps regarding AMR in plant and animal agriculture and roles of these sites as sources and sinks of AMR

\section{Knowledge gaps}

Surveillance data on the use of AMA for animal and plant health

Surveillance data on specific ARG in zoonotic agents and commensal bacteria in livestock, not only their level of AMR

Surveillance data on the amount of AMA, ARB, and their ARG in manure

Effects of different manure treatments on abundance of AMA, ARG, and ARB, as well as on frequency of HGT

Qualitative and quantitative data on sorption and fixation of AMA in soils

Quantitative data on antibiotic potency of AMA that are sorbed and fixed in soils and sediments

Persistence and eventual selection for AMR in AMA-containing soils

Chance of human-associated as well as animal-associated bacteria and pathogens to acquire AMR by MGE from commensals and environmental microbes

Quantitative data on the inoculum needed to add an ARB to the microbiomes of humans and animals

Pathways from agricultural and urban sources of AMA and ARG into sewage and the aqueous environment

Efficiency of wastewater treatment regarding elimination of ARG as well as AMA

AMA and ARB uptake in plants and influence of soil types on uptake

Direct relationship between irrigation water or manure containing ARB and ARG and the abundance and spread of corresponding bacteria or ARG on crops

Chance of human-associated as well as animal-associated bacteria and pathogens to acquire AMR by MGE from bacteria in the phyllosphere

Effects of drying or silaging roughage on the prevalence of ARG and ARB in the phyllosphere

Potential influence of direct use of AMA in plant production on contamination, selection, and spread of environmental, animal, and human resistomes

Evaluation of risk factors for selection and spread of AMR in animals and environmental reservoirs

Evaluation of transmission routes of AMR as well as human exposure data related to agricultural products

Role of biofilms in spread of ARG and ARB in the environment and food processing plants

Kinetics of spontaneous removal of ARG and ARG from soil, water, and food environments

especially antibiotics, may be present in the environment (normally within the nanograms per liter or low micrograms per liter range). For this purpose, solid-phase extraction (SPE) is the most widely used preconcentration procedure, especially in water testing. However, the need for filtration of liquids may hamper the use of this technique for waste or soil analysis.

\section{STEP 3.0. INTERPRETING RISKS AND IMPACTS ON STAKEHOLDERS}

Risk analyses regarding ARB must be performed, but such efforts require risk measurements and comparable data across different biomes: soil, plant, animal, humans, water. Only then can we analyze the more complex scientific areas of routes of transmission and antimicrobial or nonantimicrobial selective pressures and hot spots for transmission. In order for scientific data to be incorporated into a risk analysis, government policies or recommendations to prevent or minimize the transfer of ARB within agriculture from plants or feed to animals and then along the food chain to humans, as well as directly from vegetable foods to humans, such data must comply with the following requirements:
(1) Data must be comparable and gathered using standardized methods.

(2) Data must be comprehensive and sample sizes must be sufficient for statistical analysis.

With the gaps in our data and use of noncomparable methodologies, at this time it is almost impossible to develop a risk analysis based on the actual situation.

In order to understand the complex epidemiology of selection and transmission of AMR, it will be necessary to take the following steps:

(1) Define critical control points where interventions and government policies could significantly reduce the spread of AMR.

(2) Develop and measure the effects of preventive strategies.

(3) Create longitudinal studies of prevalence of AMR in commensals of livestock which consume ARB-contaminated feed.

(4) Identify the roles of feed treatments, e.g., drying, on AMR prevalence or maintenance and transfer of ARB and ARG.

(5) Analyze the food chain, not only from an anthropocentric view of AMR but also to identify animals and plants that are endpoints in the chain.

(6) Identify the relevant contribution(s) of AMA use to the development and selection of ARB within agriculture.

Once the risks have been identified, based on scientific data, we will need to rank the risks in terms of priority. Recent discussions have shown that the lack of scientific data and knowledge to fill the gaps has created differences of opinion in terms of risk priorities, even within the scientific community $(46,56)$. The risks must be measured in terms of danger to the health and welfare of animals and plants as well as humans.

\section{STEP 3.1. POTENTIAL SOLUTION}

Surveillance programs and prevalence in reservoirs. The EU system for monitoring ARB from human hospital isolates (EARSNet) was established in 1998. In 1999, the number of countries contributing data on the levels of ARB or susceptible human pathogens varied from 1 or 2 to 11 , depending on the pathogen and antibiotic resistance profile. The number of countries that provided data on all listed AMA and pathogens was very low. However, by the mid-2000s, almost all countries reported on all pathogenic ARB. The roles of EFSA and the ECDC in monitoring AMR in animals are increasing. However, the data collected are still limited to specific pathogens and resistance phenotypes. We suggest a voluntary monitoring program by researchers. This program would include the isolation of two bacterial species, E. coli and Pseudomonas aeruginosa, and the detection, or where possible the relative quantification, of a selected number of resistance genes, e.g., tet $(\mathrm{M}), a p h$, and $b l a_{\mathrm{CTX}-\mathrm{M}}$. These three suggested resistance genes cover three important antibiotic classes and have been detected in environmental, animal, and human microbiomes. These bacteria and genes are also contained within the recommendations for monitoring WWTP and environmental samples (38). The criteria used to select the resistance genes for analysis should include genes that are relevant to the antibiotic treatment of pathogenic bacteria; the genes selected should be mobile and have been identified in animal, manure, and environmental samples. Such genes pose the greatest risk to human and animal health, as they are present in pathogenic bacteria, capable of survival outside the host, and can be transferred through the food chain. While this monitoring is not an ideal approach, it is similar to the start organized by the EARS-Net project in 1999. A simple worldwide sur- 
veillance program of soil, plants, animal, water, and WWTPs utilizing the same methods would create the largest database of knowledge on AMR and could be used to generate risk analyses of different ecological compartments.

\section{FUNDING INFORMATION}

This work, including the efforts of Sophie Thanner and David Drissner, was funded by Swiss REDYMO project. This work, including the efforts of Fiona Walsh, was funded by the EPA under the EU Water JPI Stare and the DAFM under the EU ANIHWA ERA-Net project Prahad.

The funders had no role in study design, data collection and interpretation, or the decision to submit the work for publication.

\section{REFERENCES}

1. World Health Organization. 2014. Antimicrobial resistance: global report on surveillance. World Health Organization, Geneva, Switzerland.

2. Müntener C, Overesch G. 2015. Bericht über den Vertrieb von Antibiotika in der Veterinärmedizin und das Antibiotikaresistenzmonitoring bei Nutztieren in der Schweiz. Gesamtbericht 2014. Schweizerische Eidgenossenschaft, Confederation Suisse, Federal Council, Bern, Switzerland. http://www.blv.admin.ch/dokumentation/04506/04518/index.html.

3. World Health Organization. 2012. Guidelines for ATC classification and DDD assignment 2013. WHO Collaborating Centre for Drug Statistics Methodology, Oslo, Norway.

4. European Medicines Agency. 2013. European surveillance of veterinary antimicrobial consumption: sales of veterinary antimicrobial agents in 25 EU/EEA countries in 2011. Report EMA/236501/2013. European Medicines Agency, London, United Kingdom.

5. World Health Organization. 2012. Critically important antimicrobials for human medicine. WHO Press, Geneva, Switzerland.

6. Marshall BM, Levy SB. 2011. Food animals and antimicrobials: impacts on human health. Clin Microbiol Rev 24:718-733. http://dx.doi.org/ 10.1128/CMR.00002-11.

7. European Food Safety Authority, European Centre for Disease Prevention and Control. 2015. EU summary report on antimicrobial resistance in zoonotic and indicator bacteria from humans, animals and food in 2013. EFSA J 13:4036. http://dx.doi.org/10.2903/j.efsa.2015.4036.

8. Vogt D, Overesch G, Endimiani A, Collaud A, Thomann A, Perreten V. 2014. Occurrence and genetic characteristics of third-generation cephalosporin-resistant Escherichia coli in Swiss retail meat. Microb Drug Resist 20:485-494. http://dx.doi.org/10.1089/mdr.2013.0210.

9. Endimiani A, Bertschy I, Perreten V. 2012. Escherichia coil producing CMY-2 $\beta$-lactamase in bovine mastitis milk. J Food Prot 75:137-138. http://dx.doi.org/10.4315/0362-028X.JFP-11-320.

10. Overesch G, Stephan R, Perreten V. 2013. Antimicrobial susceptibility of gram-positive udder pathogens from bovine mastitis milk in Switzerland. Schweiz Arch Tierheilkd 155:339-350. http://dx.doi.org/10.1024/0036 $-7281 / \mathrm{a} 000469$.

11. Boxall AB, Blackwell P, Cavallo R, Kay P, Tolls J. 2002. The sorption and transport of a sulphonamide antibiotic in soil systems. Toxicol Lett 131: 19-28. http://dx.doi.org/10.1016/S0378-4274(02)00063-2.

12. Dolliver H, Gupta S, Noll S. 2008. Antibiotic degradation during manure composting. J Environ Qual 37:1245-1253. http://dx.doi.org/10.2134/ jeq2007.0399.

13. Kühne M, Ihnen D, Möller G, Agthe O. 2000. Stability of tetracycline in water and liquid manure. J Vet Med A Physiol Pathol Clin Med 47: 379-384. http://dx.doi.org/10.1046/j.1439-0442.2000.00300.x.

14. Massé DI, Saady NM, Gilbert Y. 2014. Potential of biological processes to eliminate antibiotics in livestock manure: an overview. Animals 4:146-163. http://dx.doi.org/10.3390/ani4020146.

15. Storteboom HN, Kim S-C, Doesken KC, Carlson KH, Davis JG, Pruden A. 2007. Response of antibiotics and resistance genes to high-intensity and low-intensity manure management. J Environ Qual 36:1695-1703. http:// dx.doi.org/10.2134/jeq2007.0006.

16. Binh CT, Heuer H, Kaupenjohann M, Smalla K. 2008. Piggery manure used for soil fertilization is a reservoir for transferable antibiotic resistance plasmids. FEMS Microbiol Ecol 66:25-37. http://dx.doi.org/10.1111/ j.1574-6941.2008.00526.x.

17. Wolters B, Kyselková M, Krögerrecklenfort E, Kreuzig R, Smalla K. 2014. Transferable antibiotic resistance plasmids from biogas plant diges- tates often belong to the IncP-1 epsilon subgroup. Front Microbiol 5:765. http://dx.doi.org/10.3389/fmicb.2014.00765.

18. Jechalke S, Heuer H, Siemens J, Amelung W, Smalla K. 2014. Fate and effects of veterinary antibiotics in soil. Trends Microbiol 22:536-545. http://dx.doi.org/10.1016/j.tim.2014.05.005.

19. Fahrenfeld N, Knowlton K, Krometis LA, Hession WC, Xia K, Lipscomb E, Libuit K, Green BL, Pruden A. 2014. Effect of manure application on abundance of antibiotic resistance genes and their attenuation rates in soil: field-scale mass balance approach. Environ Sci Technol 48: 2643-2650. http://dx.doi.org/10.1021/es404988k.

20. Ding GC, Radl V, Schloter-Hai B, Jechalke S, Heuer H, Smalla K, Schloter M. 2014. Dynamics of soil bacterial communities in response to repeated application of manure containing sulfadiazine. PLoS One 9:e92958. http://dx.doi.org/10.1371/journal.pone.0092958.

21. D'Costa VM, McGrann KM, Hughes DW, Wright GD. 2006. Sampling the antibiotic resistome. Science 311:374-377. http://dx.doi.org/10.1126/ science. 1120800 .

22. Forsberg KJ, Patel S, Gibson MK, Lauber CL, Knight R, Fierer N, Dantas G. 2014. Bacterial phylogeny structures soil resistomes across habitats. Nature 509:612-616. http://dx.doi.org/10.1038/nature13377.

23. Wellington EM, Boxall AB, Cross P, Feil EJ, Gaze WH, Hawkey PM, Johnson-Rollings AS, Jones DL, Lee NM, Otten W, Thomas CM, Williams AP. 2013. The role of the natural environment in the emergence of antibiotic resistance in gram-negative bacteria. Lancet Infect Dis 13: 155-165. http://dx.doi.org/10.1016/S1473-3099(12)70317-1.

24. Hu X, Zhou Q, Luo Y. 2010. Occurrence and source analysis of typical veterinary antibiotics in manure, soil, vegetables and groundwater from organic vegetable bases, northern China. Environ Pollut 158:2992-2998. http://dx.doi.org/10.1016/j.envpol.2010.05.023.

25. Czekalski N, Berthold T, Caucci S, Egli A, Bürgmann H. 2012. Increased levels of multiresistant bacteria and resistance genes after wastewater treatment and their dissemination into Lake Geneva, Switzerland. Front Microbiol 3:106. http://dx.doi.org/10.3389/fmicb.2012.00106.

26. Drissner D, Zürcher U. 2014. Microbial safety of fresh fruits and vegetables. In Motarjemi Y (ed), Encyclopedia of food safety, vol 3. Elsevier, Oxford, United Kingdom.

27. Bezanson GS, MacInnis R, Potter G, Hughes T. 2008. Presence and potential for horizontal transfer of antibiotic resistance in oxidase-positive bacteria populating raw salad vegetables. Int J Food Microbiol 127:37-42. http://dx.doi.org/10.1016/j.ijfoodmicro.2008.06.008.

28. Ruimy R, Brisabois A, Bernede C, Skurnik D, Barnat S, Arlet G, Momcilovic S, Elbaz S, Moury F, Vibet MA, Courvalin P, Guillemot D, Andremont A. 2010. Organic and conventional fruits and vegetables contain equivalent counts of gram-negative bacteria expressing resistance to antibacterial agents. Environ Microbiol 12:608-615. http://dx.doi.org/ 10.1111/j.1462-2920.2009.02100.x.

29. Schwaiger K, Helmke K, Hölzel CS, Bauer J. 2011. Antibiotic resistance in bacteria isolated from vegetables with regards to the marketing stage (farm vs. supermarket). Int J Food Microbiol 148:191-196. http:// dx.doi.org/10.1016/j.ijfoodmicro.2011.06.001.

30. Nüesch-Inderbinen M, Zurfluh K, Peterhans S, Hächler H, Stephan R. 2015. Assessment of the prevalence of extended-spectrum $\beta$-lactamaseproducing Enterobacteriaceae in ready-to-eat salads, fresh-cut fruit, and sprouts from the Swiss market. J Food Prot 78:1178-1181. http:// dx.doi.org/10.4315/0362-028X.JFP-15-018.

31. Duffy B, Holliger E, Walsh F. 2014. Streptomycin use in apple orchards did not increase abundance of mobile resistance genes. FEMS Microbiol Lett 350:180-189. http://dx.doi.org/10.1111/1574-6968.12313.

32. Shade A, Klimowicz AK, Spear RN, Linske M, Donato JJ, Hogan CS, McManus PS, Handelsman J. 2013. Streptomycin application has no detectable effect on bacterial community structure in apple orchard soil. Appl Environ Microbiol 79:6617-6625. http://dx.doi.org/10.1128/ AEM.02017-13.

33. Walsh F, Smith DP, Owens SM, Duffy B, Frey JE. 2014. Restricted streptomycin use in apple orchards did not adversely alter the soil bacteria communities. Front Microbiol 4:383. http://dx.doi.org/10.3389/ fmicb.2013.00383.

34. Forsberg KJ, Reyes A, Wang B, Selleck EM, Sommer MO, Dantas G. 2012. The shared antibiotic resistome of soil bacteria and human pathogens. Science 337:1107-1111. http://dx.doi.org/10.1126/science.1220761.

35. Bundesamt für Gesundheit. 2014. Eine Nationale Stratégie zur Eindämmung der Antibiotikaresistenzen. Bundesamt für Gesundheit, Liebefeld, Switzerland. 
36. Michael I, Rizzo L, McArdell CS, Manaia CM, Merlin C, Schwartz T, Dagot C, Fatta-Kassinos D. 2013. Urban wastewater treatment plants as hotspots for the release of antibiotics in the environment: a review. Water Res 47:957-995. http://dx.doi.org/10.1016/j.watres.2012.11.027.

37. O'Connor S, Aga DS. 2007. Analysis of tetracycline antibiotics in soil: advances in extraction, clean-up, and quantification. Trends Anal Chem 26:456-465. http://dx.doi.org/10.1016/j.trac.2007.02.007.

38. Berendonk TU, Manaia CM, Merlin C, Fatta-Kassinos D, Cytryn E, Walsh F, Bürgmann H, Sørum H, Norström M, Pons M-N, Kreuzinger N, Huovinen P, Stefani S, Schwartz T, Kisand V, Baquero F, Martinez JL. 2015. Tackling antibiotic resistance: the environmental framework. Nat Rev Microbiol 13:310-317. http://dx.doi.org/10.1038/nrmicro3439.

39. Gaze WH, Krone SM, Larsson DG, Li XZ, Robinson JA, Simonet P, Smalla K, Timinouni M, Topp E, Wellington EM, Wright GD, Zhu YG. 2013. Influence of humans on evolution and mobilization of environmental antibiotic resistome. Emerg Infect Dis http://dx.doi.org/10.3201/ eid1907.120871

40. Andersson DI, Hughes D. 2012. Evolution of antibiotic resistance at non-lethal drug concentrations. Drug Resist Updat 15:162-172. http:// dx.doi.org/10.1016/j.drup.2012.03.005.

41. Martínez JL, Baquero F. 2014. Emergence and spread of antibiotic resistance: setting a parameter space. Ups J Med Sci 119:68-77. http:// dx.doi.org/10.3109/03009734.2014.901444.

42. Singer RS, Williams-Nguyen J. 2014. Human health impacts of antibiotic use in agriculture: a push for improved causal inference. Curr Opin Microbiol 19:1-8. http://dx.doi.org/10.1016/j.mib.2014.05.014

43. Vogeleer P, Tremblay YD, Mafu AA, Jacques M, Harel J. 2014. Life on the outside: role of biofilms in environmental persistence of Shiga-toxin producing Escherichia coli. Front Microbiol 5:317. http://dx.doi.org/ 10.3389/fmicb.2014.00317.

44. Farkas A, Butiuc-Keul A, Ciatarâș D, Neamţu C, Crăciunaş C, Podar D, Drăgan-Bularda M. 2013. Microbiological contamination and resistance genes in biofilms occurring during the drinking water treatment process. Sci Total Environ 443:932-938. http://dx.doi.org/10.1016/ j.scitotenv.2012.11.068

45. Vorholt JA. 2012. Microbial life in the phyllosphere. Nat Rev Microbiol 10:828-840. http://dx.doi.org/10.1038/nrmicro2910.

46. Martínez JL, Coque TM, Baquero F. 2015. What is a resistance gene? Ranking risk in resistomes. Nat Rev Microbiol 13:116-123. http:// dx.doi.org/10.1038/nrmicro3399.
47. Winokur PL, Vonstein DL, Hoffman LJ, Uhlenhopp EK, Doern GV 2001. Evidence for transfer of CMY-2 AmpC $\beta$-lactamase plasmids between Escherichia coli and Salmonella isolates from food animals and humans. Antimicrob Agents Chemother 45:2716-2722. http://dx.doi.org/ 10.1128/AAC.45.10.2716-2722.2001.

48. Pruden A, Larsson DG, Amézquita A, Collignon P, Brandt KK, Graham DW, Lazorchak JM, Suzuki S, Silley P, Snape JR, Topp E, Zhang T, Zhu YG. 2013. Management options for reducing the release of antibiotics and antibiotic resistance genes to the environment. Environ Health Perspect 121:878-885. http://dx.doi.org/10.1289/ehp.1206446.

49. Jechalke S, Kopmann C, Richter M, Moenickes S, Heuer H, Smalla K. 2013. Plasmid-mediated fitness advantage of Acinetobacter baylyi in sulfadiazine-polluted soil. FEMS Microbiol Lett 348:127-132. http:// dx.doi.org/10.1111/1574-6968.12284.

50. Bailar JC, Travers K. 2002. Review of assessments of the human health risk associated with the use of antimicrobial agents in agriculture. Clin Infect Dis 34(Suppl 3):S135-S143. http://dx.doi.org/10.1086/340252.

51. Spicknall IH, Foxman B, Marrs CF, Eisenberg JN. 2013. A modeling framework for the evolution and spread of antibiotic resistance: literature review and model categorization. Am J Epidemiol 178:508-520. http:// dx.doi.org/10.1093/aje/kwt017.

52. Zhu Y-G, Johnson TA, Su J-Q, Qiao M, Guo G-X, Stedtfeld RD, Hashsham SA, Tiedje JM. 2013. Diverse and abundant antibiotic resistance genes in Chinese swine farms. Proc Natl Acad Sci U S A 110: 3435-3440. http://dx.doi.org/10.1073/pnas.1222743110.

53. Rodriguez-Mozaz S, Lopez de Alda MJ, Barceló D. 2007. Advantages and limitations of on-line solid phase extraction coupled to liquid chromatography-mass spectrometry technologies versus biosensors for monitoring of emerging contaminants in water. J Chromatogr A 1152: 97-115. http://dx.doi.org/10.1016/j.chroma.2007.01.046.

54. Richardson SD, Ternes TA. 2005. Water analysis: emerging contaminants and current issues. Anal Chem 77:3807-3838. http://dx.doi.org/10.1021/ ac058022x.

55. Ibáñez M, Sancho JV, Pozo OJ, Niessen W, Hernández F. 2005. Use of quadrupole time-of-flight mass spectrometry in the elucidation of unknown compounds present in environmental water. Rapid Commun Mass Spectrom 19:169-178. http://dx.doi.org/10.1002/rcm.1764.

56. Bengtsson-Palme J, Larsson DGJ. 2015. Antibiotic resistance genes in the environment: prioritizing risks. Nat Rev Microbiol 13:396. http:// dx.doi.org/10.1038/nrmicro3399-c1. 